\title{
Esmad, seguridad y posacuerdo: perspectivas sobre la protesta en Colombia*
}

\author{
Diego Alejandro Casas Ramírez \\ Universidad Pontificia Bolivariana, Medellín, Colombia \\ diego.casasr0@gmail.com
}

\section{RESUMEN}

El presente texto tiene el objetivo de analizar el papel que el Escuadrón Móvil Antidisturbios (Esmad) cumplirá en el posacuerdo en Colombia. Considerando el escenario de las FARC desmovilizadas, las protestas civiles y sociales comienzan a ser uno de los principales mecanismos para tramitar los conflictos y exigirle al gobierno el cumplimiento de sus principios constitucionales. En este contexto, surgen los cuestionamientos hacia el Esmad y su rol en la transición social hacia el posacuerdo. Para tal fin, este artículo se desarrolla a partir del enfoque institucionalista de la teoría política, a través de una investigación cualitativa de tipo documental y de nivel interpretativo, con el ánimo de analizar el rol que este escuadrón cumplirá en el posacuerdo. En el desarrollo de este documento se consideran los acuerdos de paz de La Habana, los debates de control político en el Congreso de la República relacionados con el tema, trabajos del Centro de Investigación y Educación Popular (Cinep) y algunas teorías y análisis de conflictólologos y de expertos en temas de seguridad y paz, tales como Ariel Ávila, Francisco Leal Buitrago y Edwin Cruz Rodríguez. Finalmente, se brindan conclusiones sobre el futuro que deberían tener los antidisturbios en la Colombia del posacuerdo.

Palabras clave: Esmad; posacuerdo; movimiento social; conflicto social; conflicto político.

Cómo citar: Casas Ramírez, D. A. (2019). Esmad, seguridad y posacuerdo: perspectivas sobre la protesta en Colombia. Ciencias Sociales y Educación, 8(16), 73-89 DOI: https://doi.org/10.22395/csye.v8n16a5 Recibido: 5 de agosto de 2019.

Aprobado: 10 de octubre de 2019. 


\section{Esmad, Security and Post-Agreement: Perspectives on Protests in Colombia}

\section{ABSTRACT}

This article aims to analyze the role of the Anti Riots Mobile Squad (Esmad in its Spanish initials) in the Colombian postagreement. Considering the scenario of a demobilized FARC, civic and social demonstrations have become one of the main mechanisms for processing conflicts and demanding compliance with their constitutional obligations to the government. In this context is where some questioning towards the Esmad and the social transition towards the post-agreement emerges. For this purpose, this article is performed under the institutionalist approach of the political theory through a qualitative and document-oriented research approach and an interpretative level, with aims towards analyzing the role this squad is going to perform in the post-agreement. The Havana peace agreements, the politic control debates regarding this matters in the Colombian Congress, the research works from the Popular Education research Center (Cinep in Spanish) and some theories and conflict-analysis made by experts such as Ariel Ávila, Francisco Leal Buitrago and Edwin Cruz Rodríguez are considered in this document. Finally, some conclusions about a desirable future for the Anti-riot forces in the Colombian post-agreement are shared.

Keywords: Esmad; post-agreement; social movement; social conflict; political conflict.

\section{Esmad, segurança e pós-acordo: perspectivas sobre o protesto na Colômbia}

\section{RESUMO}

Este texto tem o objetivo de analisar o papel do Esquadrão Móvel Antidistúrbios (Esmad) no contexto de pós-acordo de paz na Colômbia. Tendo em vista o cenário de desmobilização das Forças Armadas Revolucionárias da Colômbia (Farc), os protestos civis e sociais começam a ser um dos principais mecanismos para tramitar os conflitos e exigir do governo o cumprimento de seus princípios constitucionais. Nesse contexto, surgem os questionamentos sobre o Esmad e seu papel na transição social no pós-acordo. Para isso, este artigo desenvolve, a partir da abordagem institucionalista da teoria política, por meio de uma pesquisa qualitativa de tipo documental e de nível interpretativo, a fim de analisar o papel que o Esmad desempenhará no pósacordo. No desenvolvimento deste documento, são considerados os acordos de paz de La Habana, Cuba, os debates de controle político no Congresso da República, relacionados com a temática, os trabalhos do Centro de Pesquisa e Educação Popular e algumas teorias e análises de especialistas em conflitos e em segurança e paz, como Ariel Ávila, Francisco Leal Buitrago e Edwin Cruz Rodríguez. Por último, são apresentadas conclusões sobre o futuro que deveria ter esse tipo de organismo antidistúrbio na Colômbia do pós-acordo.

Palavras-chave: Esmad; pós-acordo; movimento social; conflito social; conflito político. 


\section{Introducción}

Actualmente Colombia está atravesando una etapa crucial para su rumbo: la aplicación del acuerdo de paz firmado en La Habana. Este momento histórico ha sido denominado por parte de algunos como posconflicto. Es un apelativo errado pues el conflicto aún existe y continuará estando, aunque se presente de otras formas y se transmita por otros medios. Como señala Monedero (2013) "existirá conflicto mientras haya seres humanos que piensen que merecen algo y no lo tienen" (p. 102).

Junne y Verokren (2005), como se citó en Ávila y Londoño (2017), mencionan que un posconflicto es una situación donde la guerra interna ha finalizado, pero dentro de la cual, se generan situaciones tensas de violencia durante décadas. Por ello, la manera más adecuada de denominar esta etapa es posacuerdo, pues al interior del territorio la guerra interna (en términos de Junne y Verokren) todavía persiste ${ }^{1}$.

Al respecto, Cruz (2016b) argumenta que: "este concepto [posacuerdo] designa con mayor precisión el período por seguir luego del eventual establecimiento de acuerdo de paz entre gobierno e insurgencia armada que el de posconflicto" (p. 10), dado que el conflicto colombiano no puede reducirse a un acuerdo parcial.

Cruz (2016b) da dos argumentos para seguir sosteniendo por qué se está atravesando por un posacuerdo y no por un posconflicto: 1) La situación de conflicto armado por la que atraviesa Colombia está dada por una serie de elementos que no son simplemente las confrontaciones armadas entre Estado y subversión. Hay un claro componente económico, político y cultural que también guarda relación con la violencia y que un acuerdo de paz no basta para solucionarlos. 2) Un acuerdo con las Fuerzas Armadas Revolucionarias de Colombia (FARC), no supone de manera inmediata la supresión de la violencia política y aquella que proviene de la criminalidad organizada que se manifiesta de distintas maneras.

El debate conceptual que se plantea entre estos dos términos (posacuerdo y posconflicto) no es un capricho ni una formalidad entre definiciones. Para el desarrollo del artículo se hace necesario enfatizar en que el posacuerdo es una etapa que le sigue a la firma de un acuerdo paz. En esta aún persisten conflictos económicos, políticos y culturales que tienen relación con las confrontaciones. La pregunta que surge en el panorama es cómo dirimir esos conflictos en la sociedad sin que se recurra al exterminio del otro.

Las FARC dejaron sus armas después de firmar en el 2016 el acuerdo con el Gobierno colombiano. Sin la presencia armada de esta organización en esta

Aún existen reductos guerrilleros (incluso de disidencias de la FARC que volvieron a las armas), estructuras paramilitares y grupos armados organizados. 
nueva etapa de Colombia, uno de los efectos más notables será un aumento de la magnitud de protestas políticas y sociales en el país ${ }^{2}$. Un ejemplo de ello pueden ser los grandes paros que se realizaron en el 2017, tan solo un año después de la firma de los acuerdos: paro cívico de Buenaventura, el paro del Magisterio y el paro del Chocó ${ }^{3}$ (paros que fueron motivados por incumplimientos del Gobierno).

La situación descrita anteriormente conlleva a cuestionar el rol que tendrá el Escuadrón Móvil Antidisturbios (Esmad) en el posacuerdo y el control de multitudes, especialmente en manifestaciones sociales y políticas que se realicen en adelante.

Por eso han surgido tres opciones en el debate público que se irán analizando en el desarrollo del artículo para el futuro de este escuadrón: 1) aumentarlo y fortalecerlo de cara a controlar las movilizaciones, como en buena medida propone la misma policía (Blu Radio, 2016). 2) Reformarlo, como en su momento sugirió la Organización Mundial Contra la Tortura (OMCT) (Garzón, 2017). 3) Desmantelarlo por completo y así estar en consonancia con una sociedad que busca salir de la violencia política. Esta última propuesta ha venido desde algunos dirigentes políticos y organizaciones sociales (Movice, 2017; Semana, 2016).

El tema del Esmad no se ha estudiado todavía a fondo en la academia. Los trabajos recientes han desarrollado lo referido a formación, estrategias institucionales y procedimientos de este cuerpo (Montealegre, 2015; Socha, 2015); las responsabilidades del Esmad en los paros agrarios (Vanegas, s. f.) y el accionar del Esmad frente a las violaciones a los derechos humanos. A partir de este contexto se pretende analizar el papel del Esmad en el posacuerdo.

Para darle respuesta a alguna de las opciones que anteriormente se mencionaron, se describirá brevemente cómo fue la creación de dicha institución y qué significado encierra la constitución de este escuadrón antidisturbios a partir de algunos análisis de autores de las ciencias sociales que han estudiado temas de conflicto, paz, violencia y seguridad en Latinoamérica y Colombia. Se analizará también cómo es el conflicto con el Esmad y su relación con la protesta social a partir de un balance de su accionar y su modus operandi, teniendo en cuenta la documentación existente sobre sus víctimas y las principales denuncias que se tienen por violación a los derechos de los protestantes. Por último, se hablará de la nueva fuerza pública que se necesita para el posacuerdo y la construcción de paz en el país. Al respecto se hacen unas conclusiones.

2 Algunas de las razones más importantes son: las diferencias con el gobierno de turno se van a tramitar por medio de paros, marchas, plantones, protestas y demás manifestaciones populares y civiles; la estigmatización se va a reducir con la entrada a la vida civil de los excombatientes.

3 Una muestra reciente de ello son los paros, las movilizaciones y las protestas que ha realizado el movimiento estudiantil y de profesores al gobierno del presidente Iván Duque como cuestionamiento a su propuesta educativa. 
Cabe mencionar que en este trabajo se entiende por protesta la definición de Taylor y Dyke, como se citó en Della Porta y Diani (2011): "espacios (sites) de contestación donde se utilizan cuerpos, símbolos, identidades, prácticas y discursos para perseguir o prevenir cambios en las relaciones institucionalizadas de poder" (p. 215).

\section{Creación del Esmad}

\section{¿Cómo surgió el Esmad?}

Este cuerpo policial data de finales del siglo XX. En el gobierno del presidente conservador de Andrés Pastrana (1998-2002) se dio origen al Esmad, exactamente el 24 de febrero de 1999. La Policía Nacional creó este cuerpo de antimotines "como una fuerza debidamente entrenada en el uso de armamento no letal y en el manejo adecuado de marchas, paros y en general todo lo relacionado con la atención de multitudes" (Rozo, 2013, p. 40).

El Esmad fue reglamentado por medio de la Directiva Transitoria 0205 de la dirección de la Policía Nacional, la cual "formalmente incorporó el concepto de seguridad ciudadana tanto en las normas que lo regulan como por el hecho de depender de la Dirección de Seguridad Ciudadana" (Cruz, 2016b, p. 103). Después, según Rozo (2013) se le dieron otras reglamentaciones a este cuerpo que surgió transitoriamente:

Mediante Resolución n. 01363 del 14 de abril de 1999, el director general de la Policía Nacional formalizó la actividad de esta unidad policial. Luego, el 5 de noviembre de 2009, el gobierno de Álvaro Uribe Vélez expidió la Resolución n. ${ }^{\circ} 03514$ firmada por el entonces ministro de defensa nacional, Gabriel Silva Luján, y el director general de la policía nacional, Mayor General Oscar Adolfo Naranjo Trujillo. Dicha resolución recibió el nombre de Manual para el Servicio de Policía en Atención a Multitudes. Tres años después, mediante la Resolución n. 02686 del 31 de julio de 2012 firmada por el general José León Riaño fue reglamentado el uso de armas de tipología "letalidad reducida". Concretamente se dio vía libre a la utilización de gas pimienta y descargas eléctricas. (p. 40)

Esta unidad también hace parte de los convenios de modernización de la policía con los cuales se dio inicio al Plan Colombia. El presidente Pastrana le apostó a una reforma militar de gran calado en medio de las negociaciones con las FARC, buscando así que como afirma Patiño (2010) "el Estado se adaptará a las nuevas exigencias de seguridad interna con las cuales este debía cimentarse y establecerse" (pp. 220-222). Frente a la falta de una política estructurada de seguridad y defensa en Colombia, según afirma Leal Buitrago (2012), se dio la imposición desde los Estados Unidos de ampliar y reorganizar el pie de fuerza, la redefinición operativa y la revisión de los procedimientos tácticos. 


\subsection{Las funciones del Esmad}

En la tabla 1 se indica cuáles son las nueve funciones policiales que los antimotines realizan en el país, buscando así cumplir su misión respecto a la seguridad del país.

Tabla 1. Funciones del Esmad

\section{Funciones del Esmad:}

A Aplicar los procedimientos de manejo y control de disturbios, multitudes, desbloqueos de vías y acompañamiento a desalojos de espacios públicos o privados, con la materialización de hechos terroristas en la jurisdicción de las unidades policiales que lo requieran, cuando su capacidad haya sido rebasada en talento humano y medios de policía.

B Asistir a las actividades de capacitación a las unidades operativas del país y escuelas de formación policial, con el fin de estandarizar los procedimientos en el control y manejo de multitudes.

C Observar durante los procedimientos lo contemplado en las normas, acuerdos y convenios de derechos humanos y derecho internacional humanitario para el uso de la fuerza que permitan restablecer el orden, la seguridad y la tranquilidad de las jurisdicciones afectadas.

D Reaccionar, disuadir y controlar los actos violentos generados por grupos de manifestantes que pretendan alterar el orden público y el buen desarrollo de las actividades sociales de alguna zona del territorio nacional.

E Realizar actividades de procedimientos comunitarios básicos de acercamiento con la comunidad, trasmitiendo el respeto, buen trato a la comunidad y protección por los derechos humanos para mejorar la imagen institucional.

F Desarrollar las actividades relacionadas con los procedimientos de policía que involucren el tratamiento a personal femenino, infantes y comunidades de género.

G Ejecutar procedimientos de control de disturbios y manejo de multitudes donde estén involucrados adolescentes, niños y personal femenino para cumplir lo establecido en las normas, leyes y acuerdos de protección de los derechos humanos y la ley de infancia y adolescencia.

H Responder por el mantenimiento y conservación del equipo de protección corporal antidisturbios asignado para el cumplimiento de la misionalidad.

I Las demás que le sean asignadas de acuerdo con la ley, los reglamentos o la naturaleza de la dependencia. 


\subsection{El trasfondo de su creación}

El asunto crucial de la creación del Esmad es el por qué se creó. La seguridad en Colombia desde mediados del siglo anterior se ha concebido con el eje de la lucha contra el comunismo internacional, específicamente en el contexto de la Guerra Fría; esto ha sido una justificación para criminalizar la protesta y la oposición política (Palacios, 2012).

A esta idea establecida bajo el periodo de la Guerra Fría (1947-1991) y la lucha contra el comunismo, Cruz (2016a) le suma la lucha contrainsurgente que no ha podido superarse en el canon militar y que por eso se ha concebido la protesta social como algo propio de lo que se ha denominado "el enemigo interno". El trasfondo de la creación del Esmad se podría resumir en una frase de Leal Buitrago (2018b), que "en muchos casos, se desdibuja el enemigo tradicional externo, propio de la guerra regular y del manejo militar para dar paso al 'enemigo interno'" (p. 162).

El Esmad es una fuerza de choque creada en un país que atraviesa por un conflicto armado con tintes políticos. Esto ha dado la impresión de que el Esmad no trata con ciudadanos, sino que se enfrenta al "enemigo interno" del país. De ahí que el Esmad no cumpla el rol de cuidar a la ciudadanía que ejerce sus derechos constitucionales, sino que actúan ligados a la idea de la seguridad nacional que combate a la subversión.

Por esa razón Leal (2018a) asegura que la práctica de esta doctrina de seguridad nacional ha considerado e incluido como problema estratégico, con frecuencia, lo relacionado con los movimientos sociales y las manifestaciones populares de protestas.

La fundación del Esmad responde a la situación que se presentaba en ese entonces en Colombia, presuntamente a las protestas ciudadanas las estaba instrumentalizando —en ocasiones infiltrando- ese supuesto "enemigo interno" del Estado. Esto hará que desde su creación y hasta el día de hoy el Esmad sea un cuerpo con sesgos y politizado. De ahí que con la inclinación contrainsurgente, tienda a confundir el ejercicio del derecho a la protesta con un repertorio de acción ligado a la insurgencia armada, propio de la concepción del "enemigo interno" (Cruz, 2016a).

En ese sentido, afirma Cruz (2016b) que:

En este país existen modelos de contención intensivos en fuerza; sesgo represivo que se explica por el legado de la militarización y de las políticas contrainsurgentes, los cuales tienen efecto sobre la formación, las mentalidades y la forma de operar de los cuerpos policiales especializados en el control de las protestas. (p. 9) 
Las inclinaciones ideológicas del Esmad han creado realidades propias, eso se nota por la caracterización que hacen del enemigo interno, pues por temas ideológicos el pensamiento distinto ha sido considerado subversivo en Colombia (Borrero, 2018).

\section{El accionar del Esmad}

\section{Algunos datos sobre las actuaciones irregulares del Esmad y las violaciones a los derechos}

Las denuncias contra el Esmad han sido por varios motivos y razones, especialmente la violación a los derechos humanos, los derechos políticos-sociales y al derecho internacional humanitario. Para este trabajo se tendrán en cuenta como bibliografía referencias, cifras y datos de varias organizaciones y colectivos, como por ejemplo el Movimiento Nacional de Víctimas de Crímenes de Estado (Movice), el Centro de Investigación y Educación Popular / Programa para la paz (Cinep / PPP), la Coordinación Colombia, Europa, Estados Unidos (CCEEU) y la Corporación Colectivo de Abogados José Alvear Restrepo (CCAJAR). También se tendrán en cuenta las cifras y los datos arrojados en los debates de control político efectuados en el Congreso de la República en los años anteriores.

A lo largo de la existencia del Esmad se han presentado unos grupos principales de víctimas de esta unidad, los cuales se identificaron y son: 1) organizaciones indígenas; 2) organizaciones campesinas; 3) participantes en protestas sociales; 4) organizaciones afrodescendientes; 5) sindicatos; 6) organizaciones estudiantiles. Los registros y las denuncias más comunes que existen contra el Esmad en cuanto a la violación de derechos a la población, son los siguientes: 1) heridos con arma blanca y elementos contundentes; 2) abusos y amenazas sexuales tanto hombres como a mujeres; 3) el empleo de elementos para la represión de la población, como lo son las balas de gomas y distintos tipos gases; 4) la desproporcionalidad de la fuerza y la autoridad; 5) tratos que están fuera de la ley por ser despiadados y atentar contra la vida digna, tales como la tortura y la humillación; 6) ataques a población vulnerable, como la niñez y la juventud; 7) retenciones ilegales por parte de agentes; 8) robos y atentados contra la propiedad privada de las personas y los bienes colectivos de la ciudadanía (Colectivo de Abogados José Alvear Restrepo, 2013; Cruz, 2016b, pp. 103-108; Uribe, 2017).

El representante a la Cámara por el partido Polo Democrático Alternativo (2014-2018) Alirio Uribe Muñoz, llevó a cabo en el año 2016 un debate de control político contra el Esmad en el Congreso de la República. En aquella ocasión el congresista exponía que esta unidad desde el periodo que va de 2002 al 2014, había cometido cuatrocientos cuarenta y ocho agresiones y presentaba un total de 3.950 víctimas. En el banco de datos del Cinep para ese periodo se reportan 
"137 casos de personas heridas, 91 casos de detenciones arbitrarias, 107 casos en los que se reportó amenazas individuales y colectivas, 13 casos de ejecuciones extrajudiciales e incluso 2 casos de violencia sexual" (Polo Democrático Alternativo, 2015). El representante Uribe Muñoz también llegó a señalar que tan solo en el 2016 se le podía atribuir al Esmad la cifra de seiscientos ochenta violaciones a los derechos humanos y seis asesinatos (Contagio Radio, 2016).

Por su parte, el informe que presentó el Movice junto a la CCEEU en el 2014, reveló que:

Durante las protestas sociales de 2013, hubo 262 detenciones arbitrarias; 485 casos de personas lesionadas; 21 casos de personas heridas, varias por armas de fuego; 12 muertos por arma de fuego y 4 desaparecidos. Además hubo 52 casos de hostigamiento y amenazas contra manifestantes y líderes sociales, y $51 \mathrm{ca}-$ sos de ataques indiscriminados contra la población civil en diferentes regiones. Solo en Antioquia fueron documentados 187 casos de agresiones, entre ellas 125 casos de agresiones y lesiones personales por parte del Esmad, y 55 casos de detenciones arbitrarias. (Hernández, 2014)

\section{Procedimientos del Esmad}

En la tabla 2 se realizan las casificaciones que hace el Esmad a los tipos de asociaciones de masas.

Tabla 2. Clasificación de multitudes

\begin{tabular}{|c|c|}
\hline Paro & $\begin{array}{l}\text { Cese de actividades laborales voluntario causado por entidades priva- } \\
\text { das o gubernamentales, generalmente sindicales, encaminadas a lo- } \\
\text { grar beneficios comunes. }\end{array}$ \\
\hline Huelga & $\begin{array}{l}\text { Acción en que los trabajadores de entidades privadas o gubernamenta- } \\
\text { les cesan las actividades laborales por determinado lapso, para presio- } \\
\text { nar acuerdos con el empleador, sea este particular, el Estado o los en- } \\
\text { tes administrativos. Esta actividad es vetada para la fuerza pública (art } \\
.219 \mathrm{CN} \text { ) y derecho constitucional protegido para la actividad laboral. }\end{array}$ \\
\hline $\begin{array}{l}\text { Asamblea } \\
\text { informativa }\end{array}$ & $\begin{array}{l}\text { Reunión de líderes o voceros para estudiar determinadas exigencias } \\
\text { que hacen los trabajadores o empleados de cualquier empresa o enti- } \\
\text { dad, con el fin de llegar a acuerdos y difundirlos. }\end{array}$ \\
\hline Taponamiento & $\begin{array}{l}\text { Bloqueo de vías o caminos con el propósito de impedir la libre movili- } \\
\text { zación de vehículos o personas, para presionar al Estado para que dé } \\
\text { soluciones a situaciones de tipo social, político o económico de una de- } \\
\text { terminada comunidad o región del país. }\end{array}$ \\
\hline Marcha & $\begin{array}{l}\text { Desplazamiento de un grupo de personas con el objeto de hacerse no- } \\
\text { tar frente al Estado, ser escuchados para que se den soluciones a sus } \\
\text { problemas. Las marchas pueden ser pacíficas o violentas, dependien- } \\
\text { do del estado de agitación que les impriman los líderes }\end{array}$ \\
\hline
\end{tabular}




\begin{tabular}{|c|c|}
\hline Manifestación & $\begin{array}{l}\text { Aglomeración o reunión pública de personas que exponen o dan a } \\
\text { conocer sus ideas, deseos y opiniones sobre determinado tema que los } \\
\text { esté afectando. Estas se pueden tornar violentas. }\end{array}$ \\
\hline Amotinamiento & $\begin{array}{l}\text { Movimiento desordenado de una muchedumbre por lo general en con- } \\
\text { tra de una autoridad. }\end{array}$ \\
\hline Invasión & $\begin{array}{l}\text { Es el ingreso de un grupo de personas a un terreno privado, con el } \\
\text { fin de asentarse y tomar posesión de este sin consentimiento del } \\
\text { dueño o morador. }\end{array}$ \\
\hline $\begin{array}{l}\text { Ocupación de } \\
\text { hecho }\end{array}$ & $\begin{array}{l}\text { Es invasión de predios urbanos o rurales sin autorización o consenti- } \\
\text { miento del dueño o morador. }\end{array}$ \\
\hline Desalojo & $\begin{array}{l}\text { Procedimiento por medio del cual las autoridades judiciales o de po- } \\
\text { licía administrativa restituyen al morador, dueño, poseedor o tenedor, } \\
\text { un bien inmueble del cual había sido despojado en abierta trasgresión } \\
\text { de las normas vigentes. }\end{array}$ \\
\hline Turba & $\begin{array}{l}\text { Grupo numeroso y denso de individuos que han sumergido temporal- } \\
\text { mente sus propias identidades en la multitud, quienes están respondien- } \\
\text { do casi de manera exclusiva, a lo que está ocurriendo en un ambiente } \\
\text { inmediato y cuyas emociones, por lo general, son de odio y cólera, por } \\
\text { lo que están en un alto nivel de excitación. }\end{array}$ \\
\hline Motín & $\begin{array}{l}\text { Movimiento desordenado y violento de una muchedumbre en contra } \\
\text { de la autoridad. }\end{array}$ \\
\hline Mitin & $\begin{array}{l}\text { Reunión donde se discuten públicamente asuntos de carácter cívico, } \\
\text { comunal, político, económico o religioso. Generalmente se desarrolla } \\
\text { en un sitio cerrado. }\end{array}$ \\
\hline Disturbio & $\begin{array}{l}\text { Accionar de turbas cuya conducta colectiva ha dado un giro hacia la } \\
\text { violencia, el vandalismo, la destrucción y el caos. }\end{array}$ \\
\hline
\end{tabular}

Fuente: adaptado de Socha (2015).

\section{¿Es el Esmad la fuerza adecuada para responder a la movilización en el posacuerdo?}

\section{El conflicto social}

En Colombia se intenta transitar de un conflicto armado a una visibilización de los conflictos políticos y sociales. En las negociaciones llevadas a cabo en Cuba, el Estado colombiano y el secretariado de las FARC entendieron esta situación, por lo que en el acuerdo de la Habana quedó consagrado la importancia de la protesta:

La movilización y la protesta pacífica, como formas de acción política, son ejercicios legítimos del derecho a la reunión, a la libre circulación, a la libre expresión, a la libertad de conciencia y a la oposición en una democracia. Su práctica enriquece la inclusión política y forja una ciudadanía crítica, dispuesta al diálogo social y a la construcción colectiva de Nación. Más aún, en un escenario de fin del conflicto se deben garantizar diferentes espacios para canalizar las demandas 
ciudadanas, incluyendo garantías plenas para la movilización, la protesta y la convivencia pacífica. Junto con la movilización y la protesta pacífica se deberán garantizar los derechos de los y las manifestantes y de los demás ciudadanos y ciudadanas. (Oficina del Alto Comisionado para la Paz, 2016, p. 44)

Por esa misma razón, el secretariado de las FARC puso sobre la mesa de La Habana la petición de eliminar el Esmad para así garantizar el derecho de la oposición a protestar libremente y a movilizarse sin afectaciones. Esta propuesta no fue aceptada y no se consagró en el acuerdo de paz ${ }^{4}$. Por el contrario, el entonces presidente Juan Manuel Santos aseguró que era necesario reforzar el Esmad en esta nueva etapa, para así contar con más seguridad en las protestas sociales que en un futuro se iban a realizar en el país (Semana, 2016).

La misma idea fue defendida por el ministro de defensa en aquellos días, Luis Carlos Villegas, quien en el debate de control político (ya mencionado anteriormente) contra el Esmad, reiteró la necesidad de seguir contando con este cuerpo policial y sugirió que lo que necesitaba era mejorar en varios aspectos, pero no desaparecer (Uribe, 2016).

Monedero (2013), haciendo referencia en un texto a las características y alcances que posee el Estado, afirma lo siguiente: "El Estado siempre es un reflejo de cómo se han solventado los conflictos históricos en el pasado y qué respuesta da en el presente a las exigencias sociales" (p. 158). A lo largo de la historia colombiana, el Estado ha tratado de silenciar o limitar la oposición política, de ahí se explica la creación del Esmad como la intención de solventar "los conflictos".

Los disensos que se van a presentar en los próximos años en Colombia no deberían ser tratados con herramientas que se diseñaron para otros contextos, para otras situaciones nacionales y otras épocas. En el presente y el futuro próximo a las exigencias sociales no se les debería responder con represión y violencia.

Al respecto de la movilización y de la protesta pacífica, el acuerdo de la Habana consagró lo siguiente: "su práctica enriquece la inclusión política y forja una ciudadanía crítica, dispuesta al diálogo social y a la construcción colectiva de Nación" (Oficina del Alto Comisionado para la Paz, 2016).

Hueso (2000), basándose en lo teorizado por Galtung, habla de tratar esos conflictos que existen en la sociedad con empatía y creatividad, no con violencia. Además señala que la existencia del conflicto no significa ausencia de paz:

$4 \quad$ El Estado colombiano, en general, no negoció con el secretariado de las FARC los temas referidos a las reformas de la fuerza pública. Ni siquiera estuvo en la agenda de la mesa de negociación de La Habana, como menciona Ávila (2015) en el artículo de Semana titulado “¿Quienes hayan sido guerrilleros pueden ser policías?”. Entre otras cosas, eso pudo haber ocurrido así por la posición de superioridad en la que llegó el Estado colombiano a negociar con unas FARC en inferioridad. Esto es diferente al caso de El Salvador en el que ocurrió lo contrario y sí se negociaron reformas a la fuerza pública de ese país. 
Los conflictos son difíciles de hacerlos desaparecer porque son fruto de la propia interacción social, ya que se originan cuando aparecen intereses incompatibles entre los diferentes actores, ya sean nacionales o internacionales. No obstante, los conflictos potencialmente pueden dar lugar a enfrentamientos, de ahí que deban crearse los mecanismos y las instituciones precisas para salvar esas incompatibilidades o al menos para encauzar las energías que impidan su aparición entre las partes involucradas. (Hueso, 2000, p. 131)

El Estado debería ir eliminando la utilización de todo tipo de violencia política, pues esos conflictos sociales no se han acabado con la firma del acuerdo de paz, por el contrario se van a agravar. Lo que habría que preguntarse es si el Esmad, en términos de Hueso (2000), es la institución adecuada para salvar esas incompatibilidades que surgen en las sociedades.

\section{Una nueva fuerza pública para el posacuerdo}

El Esmad es una fuerza que transmite a la ciudadanía el imaginario de represión y en muchas ocasiones genera inseguridad; esto podría causar distintos obstáculos en la construcción de paz en Colombia. Ávila y Londoño (2017) sostienen que las reformas al sector seguridad solo pueden funcionar si cumplen con una serie de parámetros, en primera instancia el Estado debe reconstruir la confianza de la población (p. 79) ${ }^{5}$.

Ávila y Londoño (2017) escriben en su texto que "el Departamento de Operaciones de Mantenimiento de la paz menciona que la reforma al sector de la seguridad es un proceso integral que involucra el desarrollo de instituciones más responsables, transparentes, eficientes y accesible a los ciudadanos" (p. 78).

Pese a todo, a esta institución no se le han hecho reformas de fondo, aunque se han intentado mejorar varios temas y se ha tratado de aplicar reformas blandas, por ejemplo, han ingresado mujeres a hacer parte de las filas de este cuerpo; les están dando cursos sobre derechos humanos y charlas con psicólogos para que moderen su carácter y así poder responder acertadamente a las agresiones (Orozco, 2010).

Ningún esfuerzo por mejorar la imagen que parte de la ciudadanía hacia el Esmad ha sido efectivo. Los antimotines todavía tienen esa carga negativa que está en el imaginario de la población. Por eso, difícilmente una reforma a esa unidad mejoraría la relación con la protesta y el movimiento social.

Además, sostiene que muchas de las veces en que se han cometido atropellos contra la población ha sido a causa de que se han puesto las armas al servicio de una sola visión de la sociedad. 
En su estudio sobre la seguridad en el posconflicto a partir de casos de otros países, Ávila y Londoño (2017) concluyen mencionando diez reformas que deben hacerse en dicha etapa de construcción de paz. Las más pertinentes para este trabajo son la una y la cuatro, las cuales indican: la creación de una nueva fuerza de Policía Nacional, con valores democráticos para la finalización del conflicto $\operatorname{armado}^{6}$ y la despolitización del cuerpo de Policía, pues en los casos estudiados estos cuerpos fueron un instrumento para reprimir la oposición política (Ávila y Londoño, 2017).

También es importante hacer una transición de modelos de contención en esta nueva etapa. En Colombia ha existido el modelo intensivo en fuerza, en el cual según asegura Cruz (2016b), no hay comunicación entre los manifestantes y la fuerza pública, por ende la violencia es algo habitual. En cambio, el modelo de gestión negociada que muy rara vez se ha aplicado en el país, se basa en salvaguardar los derechos de protesta, reunión y libertad de expresión (Cruz, 2016b). En este hay una constante comunicación entre los manifestantes y la fuerza pública.

\section{Conclusiones}

El movimiento social en Colombia ha desempeñado un papel fundamental frente a la democratización de la sociedad. Ha activado, estimulado y generado las otras actividades institucionales de la política y del Estado, así como sus canales de participación y expresión ciudadana. Por eso Cruz (2016b) afirma que:

La construcción de la paz y la consolidación de la democracia, que supone la exclusión de la violencia como forma de la acción política, pasan por la garantía del derecho a la protesta y de las formas de participación política de los movimientos sociales. Más aún si se tiene en cuenta la persistencia en Colombia de una exclusión sistemática de los movimientos sociales reflejada en una constante represión y criminalizados de la protesta. (p. 95)

El Esmad es un cuerpo que no debería seguir tal como está constituido, pues es claro que hoy no representa confianza para la oposición política y los movimientos sociales. Hoy por hoy representan una violencia simbólica, además de física, que no se va a solucionar fortaleciendo esta institución. La solución para acabar las violaciones de derechos humanos no pasa por aumentar el pie de fuerza o reforzar sus indumentarias y armamentos. Mientras este escuadrón siga con sus procedimientos y la represión, la violencia en las protestas no va a cesar.

Las protestas son relaciones donde no existe contrato, esto quiere decir que las manifestaciones serán deslegitimadas y perderá su estatus legal cuando alguna de las partes decida cambiar unilateralmente las reglas del juego

6 Lo cual implica cambio de doctrina, valores y principios operacionales. 
(Fillieule y Tartakowsky, 2015). Entonces se hace necesario mencionar que dentro de las protestas hay ciudadanos que cometen actos vandálicos, delictivos y violentos pero la excusa de un caso individual no puede impulsar la criminalización de toda una manifestación y se deslegitime.

Gargarella (2008) menciona que el hecho de que ocasionalmente una movilización incurra en un acto violento reprochable, no es suficiente para justificar el desconocimiento a la protesta. Los actos violentos pueden ser individualizados, de manera que la presencia de agitadores por sí misma no convierte en violenta a una manifestación (Gargarella, 2008).

Por ende, un enfoque preventivo ${ }^{7}$ sería mucho más efectivo que uno represivo. Se debería empezar por buscar una seguridad ciudadana que abandone los sesgos políticos, y enfatice en la búsqueda de la garantía de libertades y derechos de la ciudadanía.

Al Esmad ya le han intentado implementar reformas y aun así persisten los atropellos contra los ciudadanos. Una de las transformaciones más adecuadas que podría hacerse es que su rol esté aparte de las protestas políticas y sociales, y se especialice por el momento en eventos o espectáculos públicos. Colombia necesita que en el posacuerdo se concilie con la población que se manifiesta, y se individualicen las personas que cometen delitos dentro de las marchas.

Galtung habla de tratar estos conflictos con creatividad y esa es la solución que se debe tomar. Casos como los Gestores de Convivencia de la Bogotá Humana, son un ejemplo claro de lo que puede ser el trato a la protesta ciudadana para una construcción efectiva de paz; también lo que se llevó a cabo durante la alcaldía designada de Clara López Obregón en Bogotá: se negoció con la Mesa Amplia Nacional Estudiantil (Mane) para reducir los daños a terceros y al espacio público. Se hizo también un pacto con la fuerza policial y eso desembocó en una reducción notable de casos de violencia, tanto de los manifestantes como de la policía (Cruz, 2012).

Por lo anterior, es necesario comenzar a usar un modelo de gestión negociada. Este modelo tiene como prioridad la comunicación entre las partes, la reducción de formas coercitivas por parte de la policía y el respeto por la manifestación (Della Porta y Diani, 2011). Un ejemplo de esto es lo que describe Della Porta y Diani (2011):

Los representantes de los manifestantes y la policía deben reunirse con antelación a la protesta y negociar con detalle las rutas y la conducta a seguir en las manifestaciones (incluyendo las violaciones más o menos simbólicas permitidas

Este enfoque tiene como elementos claves lo referido a: "estrategias de persuasión, de negociación permanente y de aplicación blanda de la ley" (Fillieule y Tartakowsky, 2015, p. 159). 
a los manifestantes), los grupos pacíficos nunca deben ser atacados, los acuerdos alcanzados nunca deben romperse y deben mantenerse siempre abiertas las líneas de comunicación entre los líderes de la manifestación y la policía. (p. 254)

Apartar al Esmad de las protestas es necesario para que en el posacuerdo vaya desapareciendo la violencia política del escenario, además de que se apueste por:

Una paz positiva que vaya más allá de la ausencia de guerra y que, como mínimo, se traduzca en una situación en la cual la violencia sea excluida de la política y que los conflictos se transmitan por la vía de la discusión pública, la negociación y la persuasión. (Cruz Rodríguez, 2016b, p. 11)

Lo ideal para el futuro de Colombia en relación con la protesta y la seguridad de los ciudadanos, sería el desmonte total del Esmad, aunque para esto es menester que se cumplan cinco condiciones claves: 1) que haya un gobierno comprometido con la construcción de paz y que respete la oposición política; 2) que se desarme el ELN y otros reductos guerrilleros; 3) que la policía comience un proceso de reorganización en su doctrina; 4) que existan vías institucionales necesarias para que la ciudadanía pueda tramitar sus demandas; 5) la desmilitarización de la institución en muchos de sus sistemas de valores que justifican su actuación, tales como el tema operativo, doctrinal y estratégico. En palabras de Fillieule y Tartakowsky (2015) sería la "eufemización de los modos de intervención" (p. 147).

\section{Agradecimientos}

Este artículo es producto de una ponencia realizada en el V Congreso de Ciencias Políticas, en la mesa de conflicto armado, seguridad, construcción de paz y posconflicto, evento que se llevó a cabo en la Universidad Eafit del 1 al 3 de agosto de 2018.

\section{Referencias}

Ávila, A. (2015). ¿Quienes hayan sido guerrilleros pueden ser policías? Semana. Recuperado de: https://www.semana.com/nacion/articulo/la-policia-rural-de-colombia-opinion-arielavila/415921-3

Ávila, A. y Londoño, J. (2017). Seguridad y Justicia en Tiempos de Paz. Bogotá: Debate.

Blu Radio (2016). Es mejor un Esmad fuerte, pero sobre todo capacitado en DD.HH.: Gral. Rodríguez. Blu Radio. Recuperado de: https://www.bluradio.com/nacion/es-mejor-un-esmad-fuertepero-sobre-todo-capacitado-en-ddhh-gral-rodriguez-108937

Borrero, M. A. (2018). La Guerra Fría y la doctrina de la seguridad nacional. En A. Rettberg, L. Wills-Otero y A. Borrero Mansilla (ed.), Estudios sobre la seguridad nacional en Colombia I, la contribución de Francisco Leal Buitrago (pp. XVIII-XXXIV). Bogotá: Editorial Universidad Nacional de Colombia. 
Colectivo de Abogados José Alvear Restrepo. (2013). Agresiones de la fuerza pública contra la población civil en el marco del paro agrario y popular. Recuperado de https://www.colectivodeabogados. org/Agresiones-de-la-fuerza-publica

Contagio Radio. (2016). El prontuario del Esmad. Contagio Radio. Recuperado de http://www.contagioradio.com/el-prontuario-del-ESMAD-articulo-27272/

Cruz, E. (2012). La MANE y el paro nacional universitario de 2011 en Colombia. Ciencia Política, 7(14), pp. 140-193.

Cruz, E. (2016b). Fuerza pública, negociaciones de paz y posacuerdo en Colombia. Bogotá, Colombia: Ediciones desde abajo.

Cruz, E. (2016). ¿Por qué es necesario desmontar el Esmad?. Desde abajo. Recuperado de: https://www. desdeabajo.info/ediciones/item/28878-por-que-es-necesario-desmontar-el-ESMAD.html

Della Porta y Diani, M. (2011). Los movimientos sociales. Madrid: CIS.

Fillieule, O. y Tartakowsky, D. (2015). La manifestación: Cuando la acción colectiva se toma las calles. Buenos Aires: Siglo Veintiuno.

Gargarella, R. (2008). Un diálogo entre la ley y la protesta social. Derecho PUCP, 61, pp. 19-50.

Garzón, C. (2017). Una razón más para reformar el Esmad. Palabras al margen. Recuperado de http:// palabrasalmargen.com/edicion-110/una-razon-mas-para-reformar-el-esmad/

Hernández, Y. (2014). Más de 600 vulneraciones de DDHH durante las protestas sociales en Colombia. IPC. Recuperado de: http://www.ipc.org.co/agenciadeprensa/index.php/2014/07/10/masde-600-vulneraciones-de-ddhh-durante-las-protestas-sociales-en-colombia/

Hueso, V. (2000). Johan Galtung. La transformación de los conflictos por medios pacíficos. Cuadernos de estrategia, 111, pp.125-159.

Junne, G. y Verokren, W. (eds.). (2005). Postconflict Development: Meeting New Challenges. Boudler: Lynne Rienener Publishers.

Leal, F. (2012). Eficacia de la Fuerza Pública y adecuación de sus estrategias: ¿Hacia una paz sostenible? (Primera parte). Razón pública. Recuperado de: https://razonpublica.com/index.php/ conflicto-drogas-y-paz-temas-30/2701-eficacia-de-la-fuerza-publica-y-adecuacion-desus-estrategias-ihacia-una-paz-sostenible-primera-parte.html

Leal, F. (2018a). El oficio de la guerra. La seguridad Nacional en Colombia. En A. Rettberg, L. Wills-Otero y A. Borrero Mansilla (eds.). Estudios sobre la seguridad nacional en Colombia I. La contribución de Francisco Leal Buitrago (pp. 5-11). Bogotá: Editorial Universidad Nacional.

Leal, F. (2018b). Elementos para una redefinición de la seguridad nacional. En A. Rettberg, L. Wills-Otero y A. Borrero Mansilla (eds.). Estudios sobre la seguridad nacional en Colombia I. La contribución de Francisco Leal Buitrago (pp. 153-180)- Bogotá: Editorial Universidad Nacional de Colombia.

Monedero, J. C. (2013). Curso Urgente de Política para Gente Decente. Bogotá: Planeta.

Montealegre, G. A. (2015). Análisis de la problemática que enfrenta el grupo de Escuadrones Móviles Antidisturbios (Esmad) Bogotá Policía Nacional durante los procedimientos de control de multitudes. Recuperado de http://hdl.handle.net/10654/7166.

Movice. (2017). 5. Reforma a la Policía Nacional y Desmonte del Esmad [Archivo de Video]. Recuperado de https://www.youtube.com/watch?v=wt-mxKkIyRE 
Oficina del Alto Comisionado para la Paz. (2016). Acuerdo Final Para La Terminación Del Conflicto Y La Construcción De Una Paz Estable Y Duradera. Recuperado de http://www.altocomisionadoparalapaz.gov.co/procesos-y-conversaciones/Documentos\%20compartidos/2411-2016NuevoAcuerdoFinal.pdf

Orozco, Y. (2010). El Escuadrón Móvil Antidisturbios y la protección de los derechos humanos (tesis de maestría). Universidad Militar Nueva Granada, Bogotá, Colombia. Recuperado de: https://repository.unimilitar.edu.co/bitstream/handle/10654/5284/OrozcoMunozYahajaira2010. pdf? sequence $=2 \&$ is Allowed $=y$

Palacios, M. (2012). Violencia pública en Colombia, 1958-2010. México, D.F.: Fondo de Cultura Económica.

Patiño, V. C. A. (2010). Guerra y construcción del Estado en Colombia 1810-2010. Bogotá: Debate.

Policía Nacional. (s. f.). Funciones de los Escuadrones Móviles Antidisturbios de la Policía Nacional. Recuperado de: https://www.policia.gov.co/especializados/antidisturbios/funciones

Polo Democrático Alternativo. (2015). Representante Alirio Uribe cita a debate sobre extralimitación de funciones del Esmad. Recuperado de https://www.polodemocratico.net/nuestrasnoticias/102-titulares/9213-representante-alirio-uribe-cita-a-debate-sobre-extralimitacion-de-funciones-del-ESMAD

Rozo, W. (2013). Esmad, arma letal. Cien días vistos por el Cinep/PPP, (80), 39-43.

Semana. (2016). Respaldo de Santos al Esmad genera polémica. Semana. Recuperado de https:// www.semana.com/nacion/articulo/proceso-de-paz-santos-fortalecera-ESMAD-parael-posconflicto/479858

Socha, J. (2015). La "aplicación de estrategias administrativas de marketing para la prevención y respeto de los derechos humanos en el Escuadrón Móvil Antidisturbios "Esmad-Bogota" (tesis de grado). Universidad Militar Nueva Granada, Bogotá, Colombia. Recuperado de https://repository. unimilitar.edu.co/bitstream/handle/10654/7134/estrategiass\%20de\%20marketing\%20respeto\%20 ddhh\%20esmad.pdf?sequence=1\&isAllowed=y

Uribe, M. A. (2017). Escuadrón Móvil Antidisturbios Esmad: ¿Garantía de protección? Recuperado de: https://prezi.com/nz8kicgtf96_copy-of-escuadron-movil-antidisturbios-esmad-garantiade-proteccio/

Uribe, A. (2016). Ministro de Defensa Luis Carlos Villegas [Archivo de Video]. Recuperado de https: https://www.youtube.com/watch?v=ayCZ8fOUDw\&index=5\&list=PLGP6NjTaRcblC58vi0x_LCnLPWEqtNYB

Vanegas, A. (s. f.). Responsabilidad del Esmad por abusos de la autoridad en los paros agrarios (tesis de maestría). Universidad Santo Tomas, Bogotá, Colombia. Recuperado de: https://repository.usta.edu. co/bitstream/handle/11634/2038/Vanegasadriana2017.pdf?sequence=1\&isAllowed=y 